\title{
Design and Optimization of Wing Structure for a Fixed-Wing Unmanned Aerial Vehicle (UAV)
}

\author{
Jiawen Yu \\ Ranney School, Tinton Falls, NJ, USA \\ Email: 1904244083@qq.com
}

How to cite this paper: Yu, J.W. (2018) Design and Optimization of Wing Structure for a Fixed-Wing Unmanned Aerial Vehicle (UAV). Modern Mechanical Engineering, 8, 249-263.

https://doi.org/10.4236/mme.2018.84017

Received: August 22, 2018

Accepted: November 18, 2018

Published: November 21, 2018

Copyright $\odot 2018$ by author and Scientific Research Publishing Inc. This work is licensed under the Creative Commons Attribution International License (CC BY 4.0).

http://creativecommons.org/licenses/by/4.0/

\begin{abstract}
The wing, one of the most important parts of aircraft, always requires sophisticated design to increase lift, reduce drag and weight. For modern fixed-wing $\mathrm{UAV}$, extending cruising time is always a requirement for the overall design. Designing a most light wing that can match the requirements of work conditions is desired. In this work, according to the work conditions, we compare several types of wing and chose beam-type wing. Then we made the detailed design and optimization to reduce the weight of wing. At last, we draw the 3D model for potential realistic production.
\end{abstract}

\section{Keywords}

Wing Structure, Optimization, 3D Model Design

\section{Introduction}

One of the most crucial parts of an aircraft is wing. A wing is a type of fin that produces lift, while moving through air or some other fluid. The quality of the wing design determines the overall performance of the aircraft to a large extent [1].

The task of structural design is to design a specific wing structure, which can meet tactical technical requirements or develop the requirements of the contract task. This includes the plane shape of the wing surface, airfoil configuration, the relative position of the wing body and the location of the interior of the wing. The wing structure has several typical structural forms: Beam type, single block type, multi-ventral plate type and hybrid type. Other wing structures are their combination or development [2].

The design of the wing is developing through the past century. For example, the wing of the Wright aircraft (Figure 1) is significantly different from modern aircraft, such as Boeing 787 (Figure 2). The quantity, shape, size and material of 


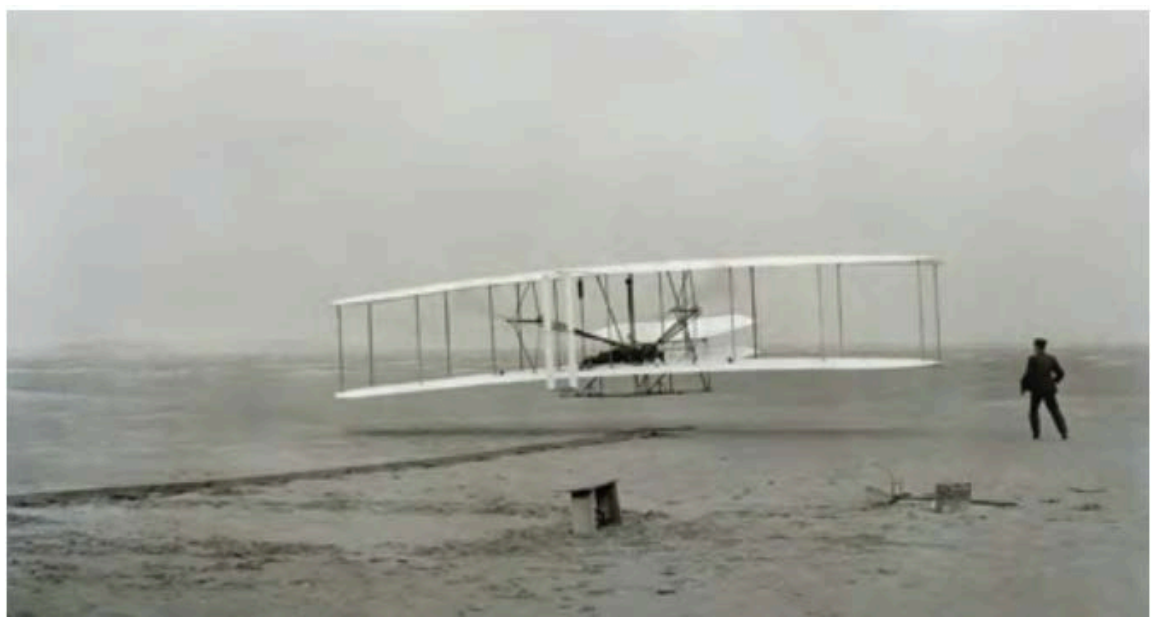

Figure 1. The aircraft designed by Wright Brother.

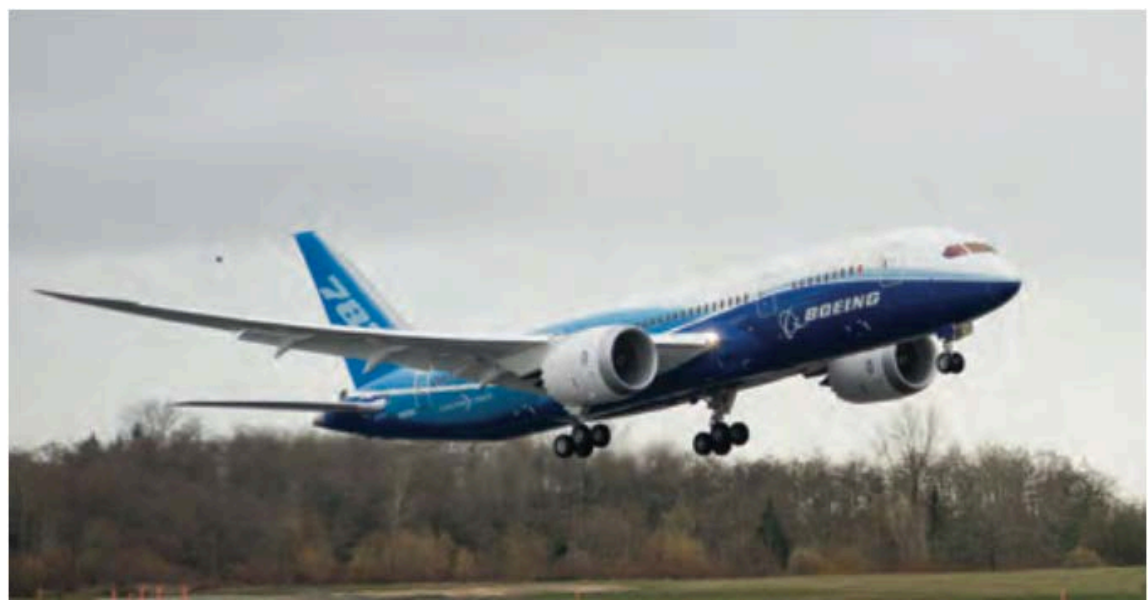

Figure 2. Boeing 787.

the lift surfaces will affect the performance of the aircraft.

Since 1930s, NASA and its predecessor, NACA, have been at the forefront of the design of the wing. Their development of the basic wing shapes has become the first choice for the major aero-nautical manufacturer. They are playing a critical role to nowadays air travel.

For this project, the task is to design and optimize a wing based on the design task book. The goal is to design a wing with the lightest weight that can satisfy strength, stiffness and life requirements. For an aircraft, the wing structure accounts for $25 \%-50 \%$ of the aircraft body mass, which accounts for $8 \%-15 \%$ of the whole aircraft quality. Also, the wing occupies $30 \%-50 \%$ of the total air resistance of the aircraft. According to these statistics, a suitable wing is crucial to the performance of the whole aircraft [3].

As mentioned, the goal of designing a wing is to minimize the weight of the wing under the premise that the wing strength meets the requirements of deflection, stiffness and strength. In this project, we involve optimization, modeling, finite element analysis and so on, which is helpful to our understanding of air- 
craft design profession and occupation.

The traditional wing design experience is very abundant. The founder of the wing design is mainly the American NASA and its predecessor NACA. The four digits and the five digits airfoil library that developed by NASA has a very important place in the aviation history. Many aircraft design and airfoil are selected directly from the airfoil.

When it comes into twenty-first Century, the design of the aircraft involves the support of computer. Not only the structural strength of the aircraft was guaranteed, but also the reliability and weight of the aircraft are strictly controlled [4] [5] [6] [7] [8].

The corresponding intelligent materials are also being developed to seek the rapid response of aircraft to aeroelastic changes, or the use of variable wings to study the form of aircraft wing damage.

In a word, the aircraft wing is a vital component of the aircraft, which has great influence on the performance of the aircraft.

This wing design requires the design of a small wing with a chord length of $200 \mathrm{~mm}$, a ratio of 5 to a chord, and a sweep angle of 30 degrees.

The load of the wing is set according to the wing load and the wing area of the Cessna 152 small aircraft. The wing is subjected to lift $100 \mathrm{~N}$ and resistance $50 \mathrm{~N}$. The deflection of the wing is defined according to the relative deflection of 0.08 , and the final allowable deflection is $30 \mathrm{~mm}$.

The allowable stress of the wing is divided by the ultimate stress of the material by the safety factor, in which the material performance is like the table and the safety factor is 1.5. At this time, the allowable stress is $270 \mathrm{Mpa}$ (Table 1).

\section{Wing Structure}

According to the task requirements, we plan to design a straight beam wing. The structure is shown below in Figure 3.

A straight beam wing is mainly consisted of skin, wing rib and wing beam. Skin forms a streamlined outer surface of the wing that take part in the airframe's force. In order to ensure the smoothness of the surface, the skin should have sufficient lateral bending stiffness. The skin can be combined with the stringer to form an integral panel to bear normal stress. The function of wing rib is to form the shape of the wing profile. It is connected to the truss and skin and provides vertical support to the truss and skin in the stiffness of its own plane. Wing beam is a simple load bearing structure that can support shear force $Q$ and bending moment $\mathrm{M}[9]$

In this work the process to design the wing structure is: 1) Select the airfoil

Table 1. Material properties.

\begin{tabular}{cccc}
\hline \multirow{2}{*}{ Material } & Young's Modulus (E) & Passion's ratio $(v)$ & density $(\mathrm{p})$ \\
\cline { 2 - 4 } & $\mathrm{MPa}$ & $\mathrm{Kg} / \mathrm{m}^{3}$ \\
\hline LD5 Aluminum Alloy & 71000 & 0.33 & 2750.0 \\
\hline
\end{tabular}




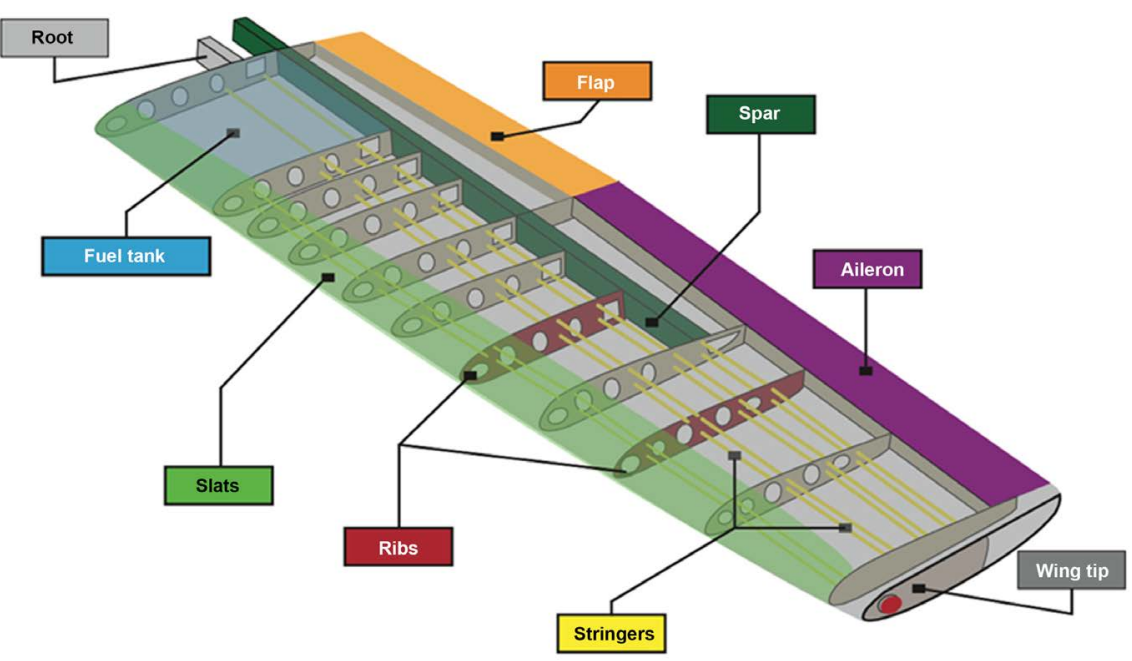

Figure 3. Structure of a straight beam wing [4].

shape from the airfoil library (NACA). 2) Choose the most efficient wing structure according to the conditions. 3) Design the rib on the wing structure according to the airfoil shape. 4) Design other parts in the wing structure. 5) Optimize the whole structure to the wing's weight.

\section{Design Process}

Wing design includes shape design and structural design. The shape of the wing is designed according to the tactical, technical and performance requirements of the aircraft, and the main geometric parameters of the wing are determined. The wing structural design is according to the basis provided by the aircraft overall design stage (including the shape design), to design a specific wing structure that can meet all the requirements. Specifically, the design process of the wing is that according to the original basis, choose the force form of the wing reasonably, arrange the main force components of the wing, determine the dimensions of the longitudinal components along the sections, and design the main force components.

The original basis of wing design is shown in Figure 4.

There are two steps for wing structure design: proofing design and detailed design. Proofing design include the internal arrangement of the wing, the design of the separation plane, the selection of the structural type, the arrangement of the main force components, the drawing of the airfoil theoretical map and the proof drawing. Detailed design including the wing parts and components design. That is a process from parts, components to complete set of production drawings. And finish the calculation of total strength, stiffness and life of the wing. The detailed steps are: 1) Calculation of external load and internal force. 2) Internal arrangement, determine the structure type, design separation plane, docking mode, arrange the main force components, draw the proofing map. 3) Design calculation and design the strength of each component. 4) Draw the theoretical map of the wing. 5) Design of wing structural elements. 6) Calculation 


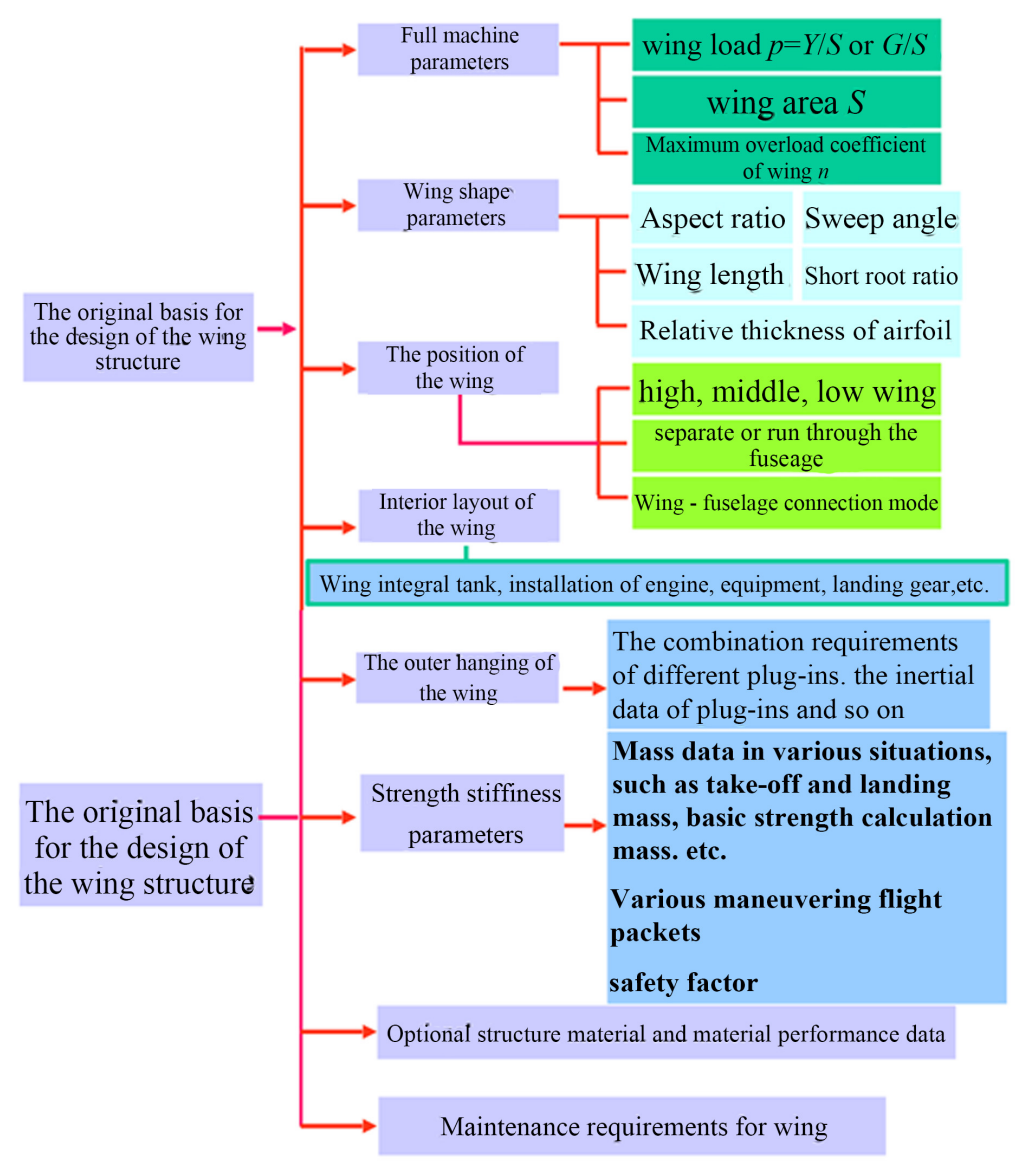

Figure 4. The original basis of wing design.

of structural strength and stiffness. 7) Draw production drawings. 8) Calculate the fatigue life and inspection period.

\section{Different Types of Wings}

In modern aircraft design, wing structure must be considered in the overall stage. So that we choose the type of wing carefully. After the overall scheme is determined, the structural type of the components and the layout of the main load elements are basically determined, and no modification is allowed in the structural design.

\subsection{Beam Type}

There are strong wing beams in the longitudinal direction, thin skins and weak girders. The edge section of beams is much larger than that of long truss sections. Its advantages are that the structure is simple, the opening on the skin is convenient, the opening has little influence on the bending capacity of the structure, and the connection is simple, and the docking point is small. The disadvantages are that he skin cannot play the role of bending, material utilization is not sufficient, the skin is easy to lose stability, influence the quality of air flow, increase resistance, and easily lead to early fatigue damage and low survivability. 


\subsection{Single Block Type}

For this type, the stringer is longer and stronger, the skin is thicker, and the wing rib is denser. The section area of the general beam bar is usually not large, and sometimes only the longitudinal wall is arranged.

The advantage of this type of wing is that the skin deformation is small, and the air flow quality is high when aerodynamic load is applied. The material is dispersed to the outer edge, and the bending resistance, torsional strength and stiffness are all improved. The safety and reliability are good. The disadvantage is that the structure is complex and sensitive to the opening and the connection is complex because it has more joint points with the middle wing or the fuselage.

\subsection{Multi-Ventral-Plate-Type}

This type of wing is equipped with more longitudinal walls with thicker skin. The thick skin bears all the bending moments. The advantage is that the flexural material is distributed on the upper and lower edges of the section, with high structural efficiency, large local stiffness and overall stiffness. Also, this kind of wing have high dispersion of the force, good safety damage and high survivability. The only disadvantage is that it is not suitable for large opening and there are a large number of connection points with the fuselage.

The main difference between the three types of wing type of wing is that the dispersion of the area of the positive stress element caused by bending moment is different, so when the total area of the element is at the same time, the center distance of the latter is higher, the structure efficiency may be higher, and the weight may be lighter. Further analysis is needed for the specific situation.

Here we choose the beam type for this mission. For this wing we begin from the layout of the main force components, which includes mode, quantity and position. For main force components, they include beams, walls, stiffeners, common ribs, stringers, etc.

Some examples of planes and their wing type data is shown below in Table 2.

The characteristics of the various wing structural types, and the relative load

Table 2. Different wing types.

\begin{tabular}{ccccccc}
\hline Plane type & F-86D & Mig-15 & F-104 & B-707 & L-29 & Mirage-III \\
\hline $\begin{array}{c}\text { wing type } \\
\text { Relative }\end{array}$ & Sweep back & Sweep back & Straight & Sweep back & Straight & Triangle \\
$\begin{array}{c}\text { Thickness } \\
\text { Relative load } \\
\left.\text { ('10 } 10^{5}\right)\end{array}$ & $11.5 \%$ & $10.4 \%$ & $3.36 \%$ & $12 \%$ & $17 \%$ & $4 \%$ \\
$\begin{array}{c}\text { Effective height } \\
\text { ratio (\%) }\end{array}$ & 4.70 & 3.62 & 5.85 & 19.3 & 2.12 & 0.82 \\
$\begin{array}{c}\text { Wing Structure } \\
\text { Single block Single block }\end{array}$ & $\begin{array}{c}\text { Multi ventral } \\
\text { plate }\end{array}$ & Single block & Beam & Multi-Beam \\
\hline
\end{tabular}


and effective height ratio are considered purely from the structural point of view. In fact, the choice of structural load types is largely influenced by many factors in the overall layout of aircraft and needs comprehensive measurement. The first aspect is about internal layout of wing, such as retractable landing gear, large openings, etc. The second aspect is the relative position of the wing and the fuselage, as well as the interior of the fuselage. The third aspect is the geometric parameters of the wing, such as swept wing, delta wing, etc.

The layout of the main force components of the wing includes quantity and location of the main force components of the wing. The main force components are beams, walls, stiffeners, ordinary ribs, stringers and so on. The principle of the layout of the main force components is to ensure the bending, shear and torsion caused by aerodynamic load can be transmitted to the fuselage smoothly and reliably. At the point of concentrated force and concentrated torque, the corresponding components (reinforced rib, auxiliary short beam, etc.) should be arranged. The concentrated force is diffused; the distributed force after diffusion is transmitted to the stress box section of the wing structure, and then the load is transmitted to the fuselage at the base of the wing. Generally, the more direct the force is, the lighter the weight of the structure is. The layout of reinforced members should be made comprehensively to reduce weight.

Here we choose the beam type for this mission. For this wing we begin from the layout of the main force components, which includes mode, quantity and position. For main force components, they include beams, walls, stiffeners, common ribs, stringers, etc.

\section{Design Methods}

This design relies on finite element software Ansys, COMSOL as well as graphics software SolidWorks, Catia and Inventor. We use the finite element models to analyze distribution of stress and strain, and then optimize the design.

The design steps are as follows:

1) COMSOL Multiphysics + SolidWorks. Because the modeling of COMSOL is relatively simple, the interface is friendly, and the results are more content. Therefore, the initial analysis of the use of COMSOL can let us have an intuitive understanding of the overall distribution of the wing load. Then we can determine the position of the wing beam and the position of the wing ribs as well as quantities of the wing ribs (Figure 5 \& Figure 6).

2) Ansys + Inventor. The position of the wing beam and the web is determined by the preliminary results. After that we draw the wing structure with Inventor, and then we input that to Ansys (Figure 7). According to the design requirements, we apply grid and loading to the model properly. The Shell unit and Beam unit of Ansys are used to cover the plane of the Inventor (Figure 7), and the optimization design is carried out for the body of the wing. The object in the optimization model is to make the volume of the wing smallest. Under the corresponding constraints, the weight of the wing is also the lightest. 


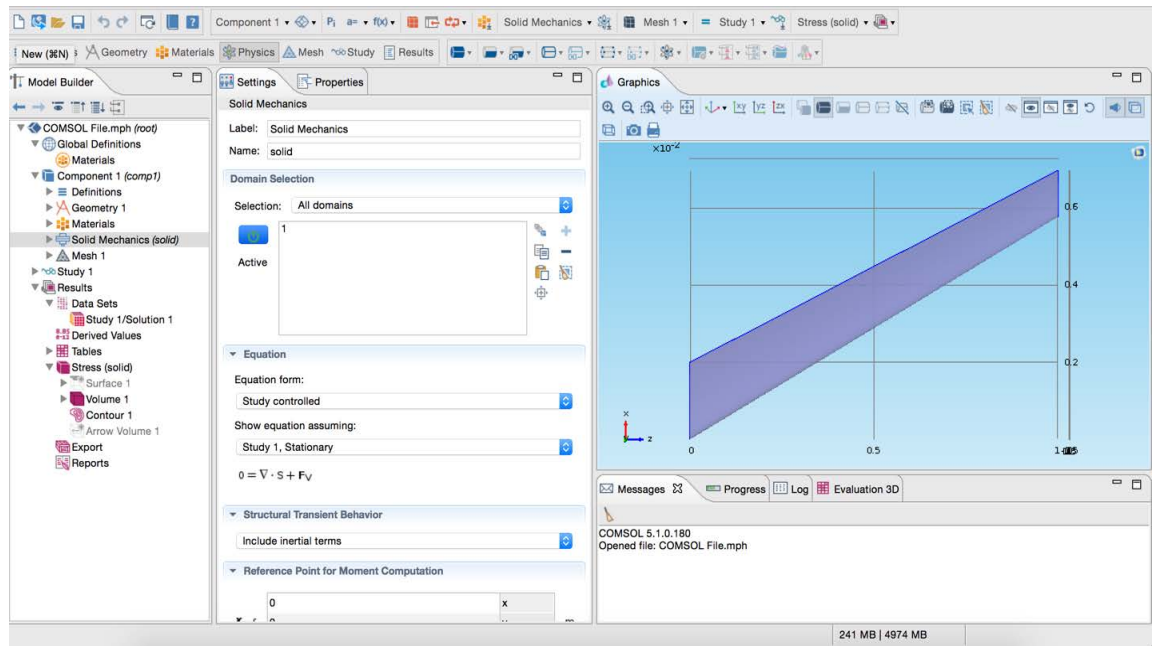

Figure 5. Settings of COMSOL model.

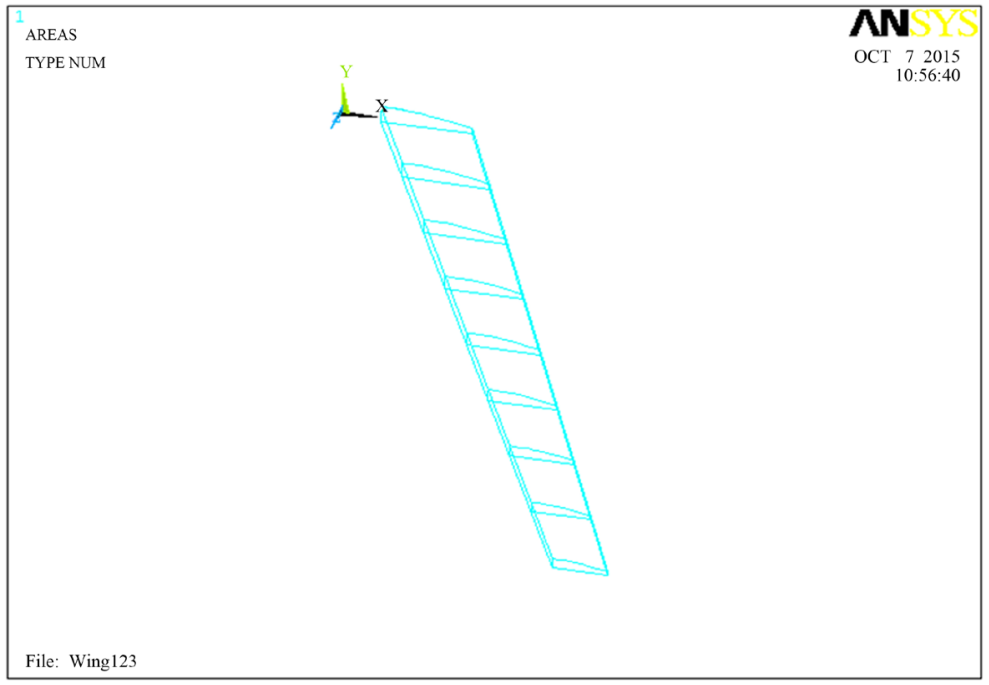

Figure 6. Model outline in Ansys.

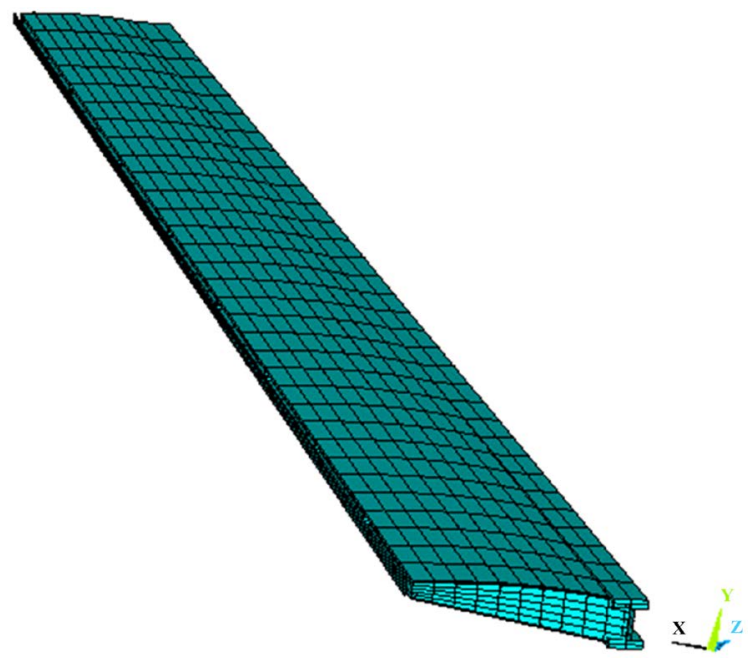

Figure 7. Mesh of the model in Ansys. 
3) Catia. After the structural parameters of each part of the wing are determined. We use Catia to draw the parts. The drawings can be produced directly if necessary.

\section{Results and Discussions}

\subsection{COMSOL Multiphysics Results}

In COMSOL, we apply lift and drag force to certain points according to design requirements. After calculation with the element model, we observe the stress and strain distribution of the wing. The results show that the maximum strain of the wing is concentrated on the $1 / 4$ string strength. The strain on the root of the wing is distorted and complex (Figures 8-10).

As a result, the following design can be obtained:

1) The beam type wing structure is adopted, and the beam is on the $1 / 4$ string length.

2) In the real wing structure, there need to be flapped and aileron, so the web is at the $85 \%$ string length.

3) Because the wing is small, the skin can be stable without using or using less trusses.

\subsection{Ansys Results Analysis}

Set the initial parameters to optimize the wing. The parameters are set as shown in the form (Table $3 \&$ Table 4 ).

The results are shown in the figures (Figures 11-16).

Table 3. Parameters and notations.

\begin{tabular}{cc}
\hline B & Trusses width \\
H & Trusses height \\
T1 & Thickness of web \\
T2 & Thickness of beam web \\
T3 & Wing rib thickness \\
TS & Thickness of skin \\
\hline
\end{tabular}

Table 4. Optimization results and range.

\begin{tabular}{cccc}
\hline Parameter symbol & Parameter name & Optimization results & Optimization range \\
\hline B & Width of trusses & $18.86 \mathrm{~mm}$ & $5-20 \mathrm{~mm}$ \\
H & Height of trusses & $5.00 \mathrm{~mm}$ & $2-10 \mathrm{~mm}$ \\
T1 & Thickness of web & $6.62 \mathrm{~mm}$ & $5-10 \mathrm{~mm}$ \\
T2 & Beam web thickness & $5.41 \mathrm{~mm}$ & $5-10 \mathrm{~mm}$ \\
T3 & Wing rib thickness & $1.21 \mathrm{~mm}$ & $0.5-3 \mathrm{mmm}$ \\
TS & Thickness of skin & $2.23 \mathrm{~mm}$ & $0.5-5 \mathrm{~mm}$ \\
DMAX & Maximum pressure & $86 \mathrm{MPa}$ & less than $270 \mathrm{MPa}$ \\
DY & Maximum deflection & $30.15 \mathrm{~mm}$ & less than $30 \mathrm{~mm}$ \\
\hline
\end{tabular}




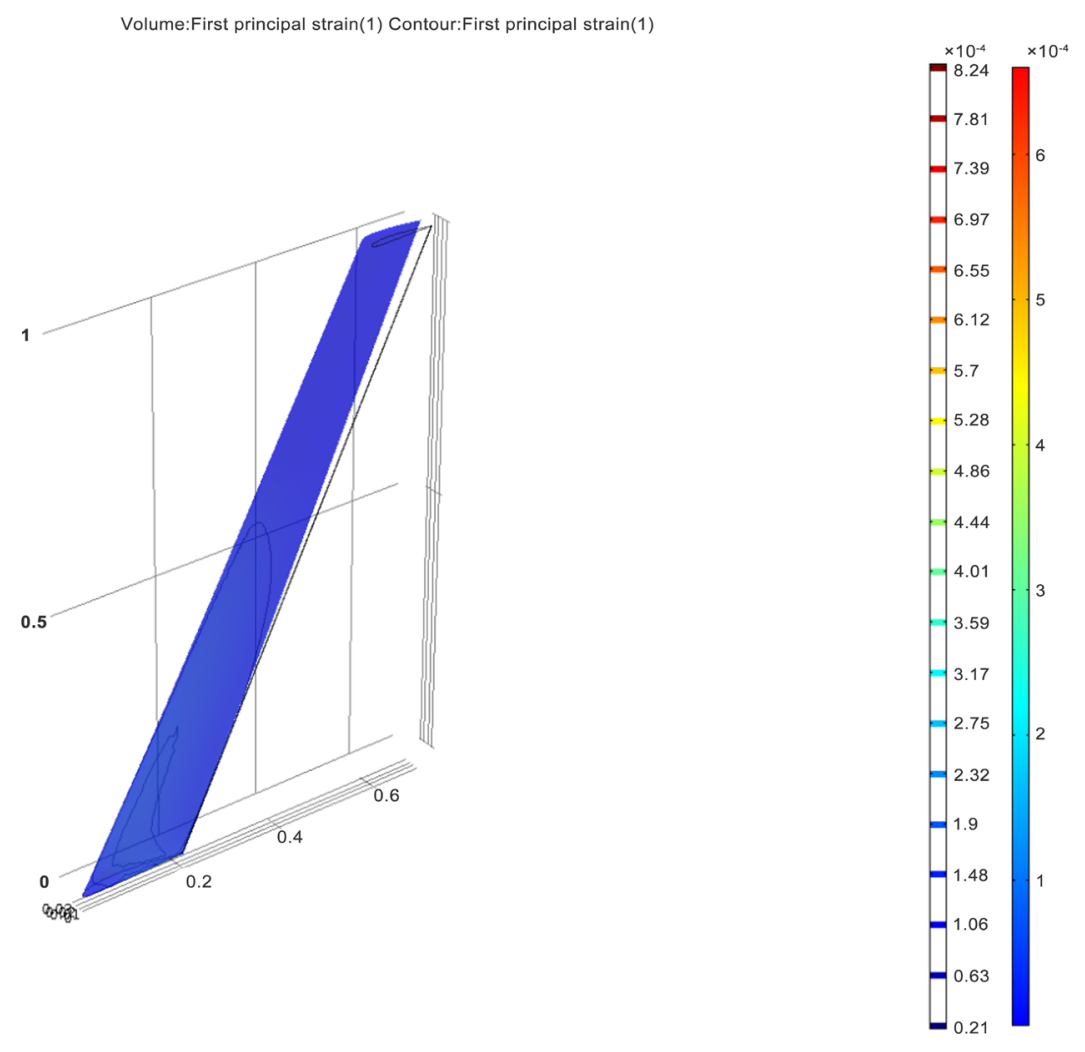

Figure 8. First principle strain cloud map.

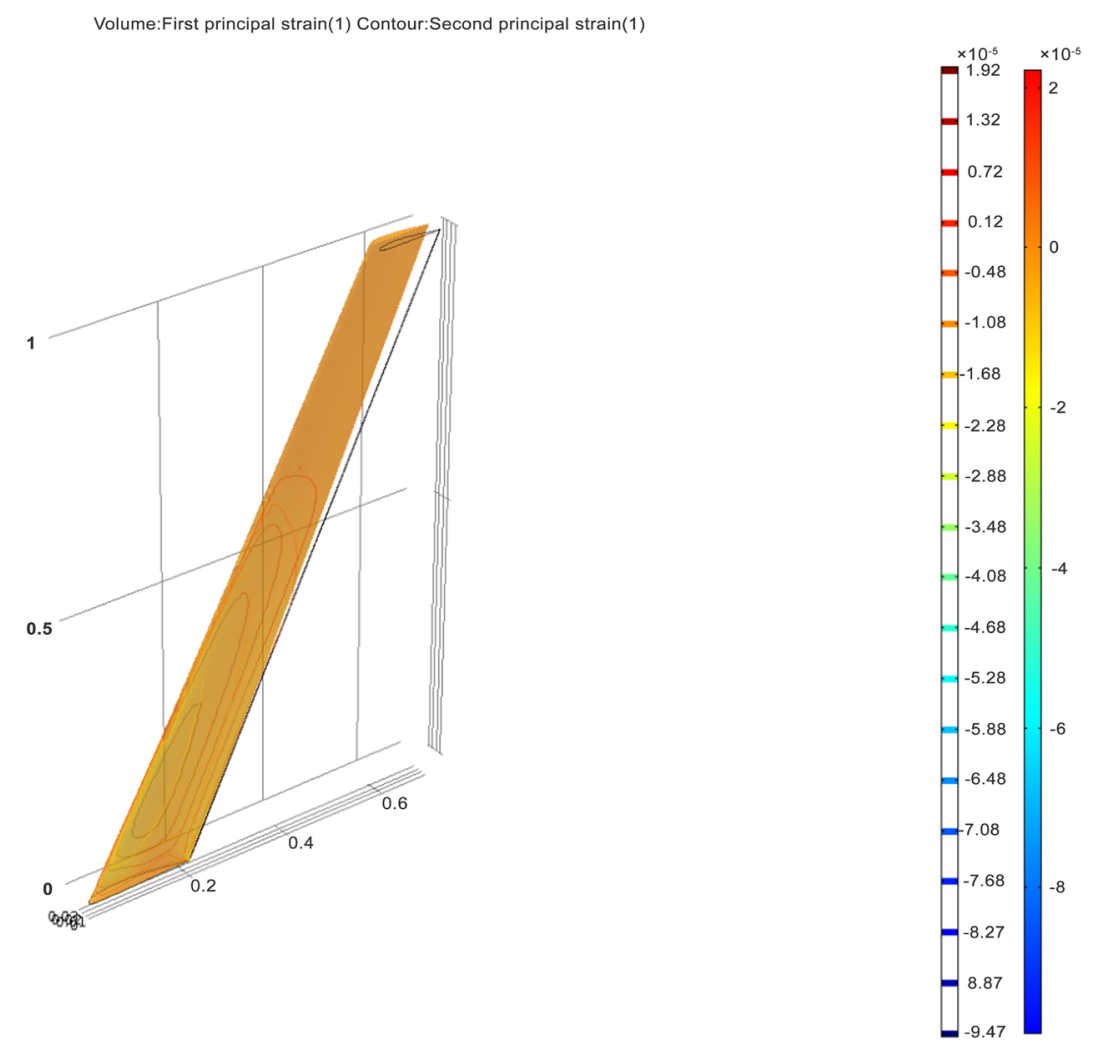

Figure 9. Second principle strain cloud map. 


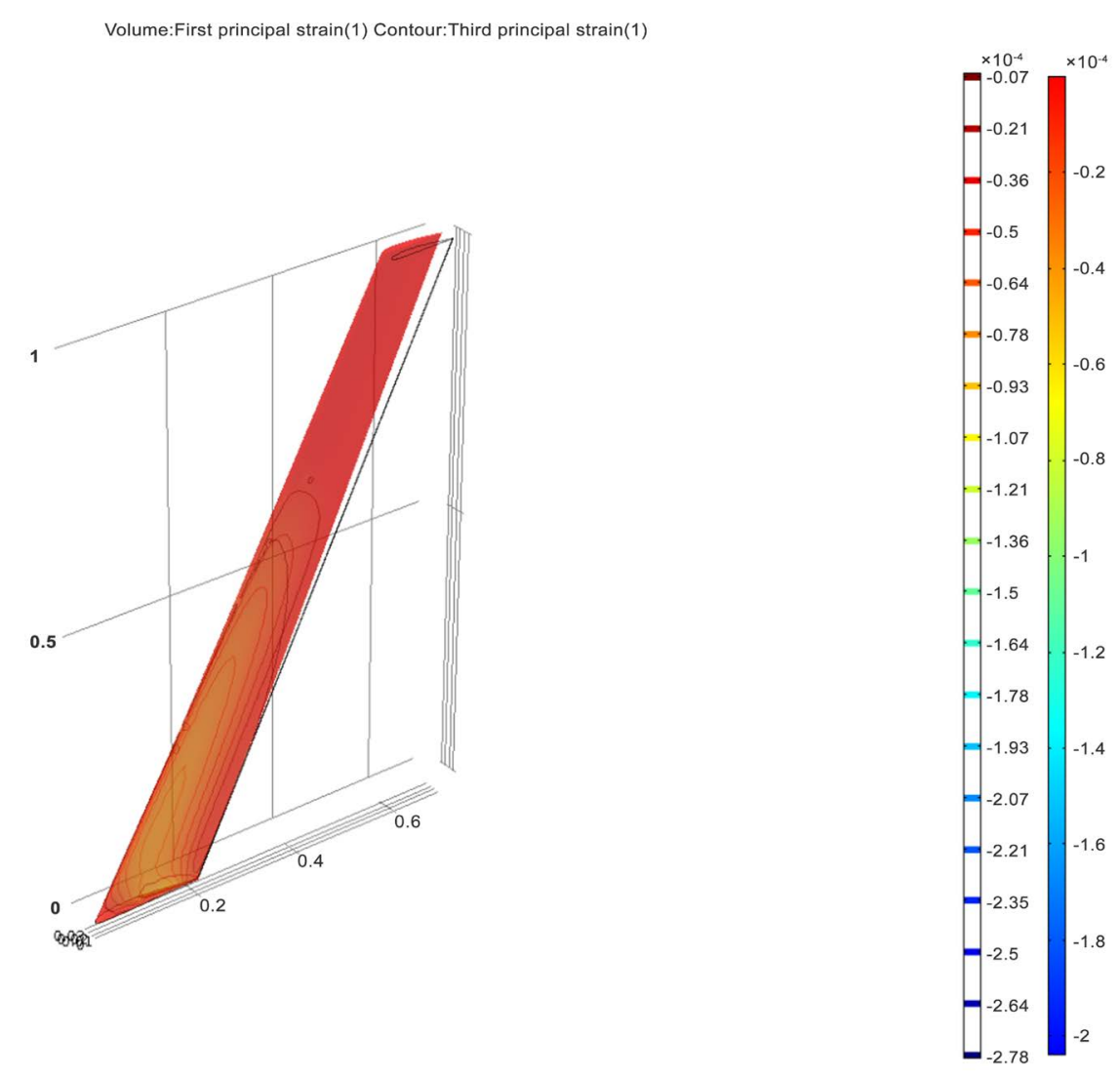

Figure 10. Third principle strain cloud map.

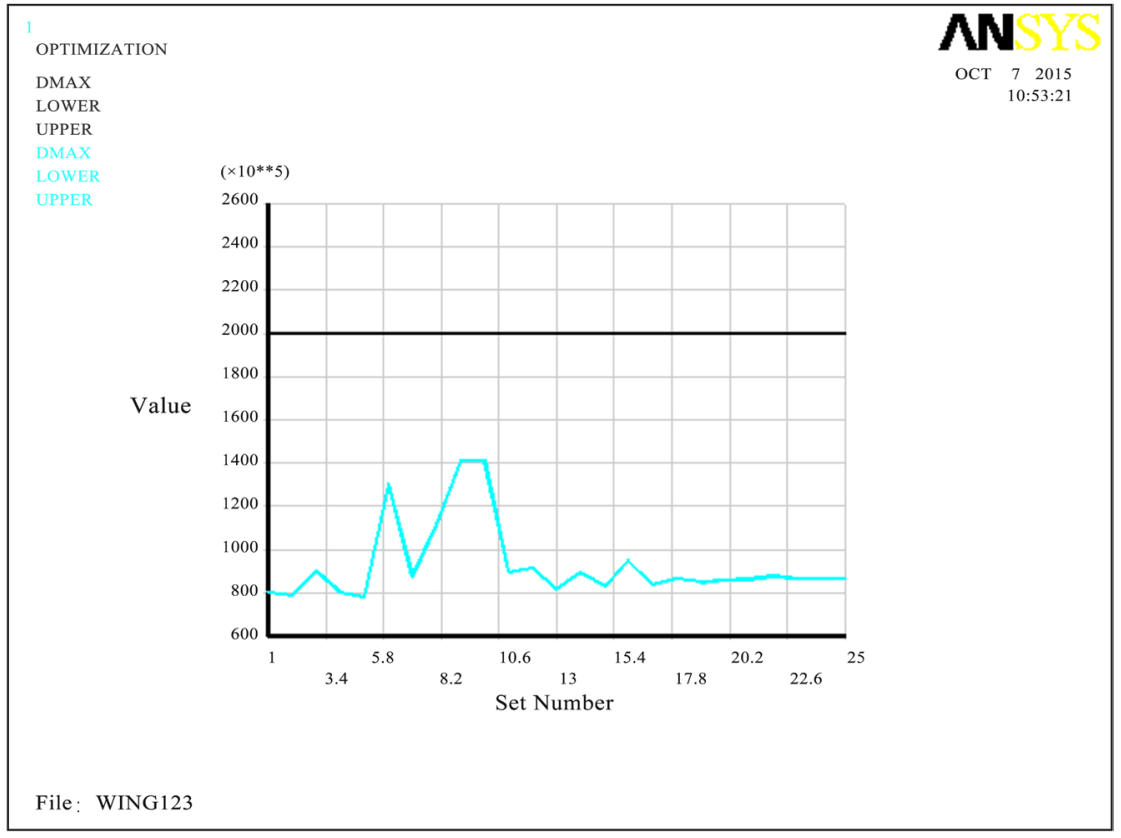

Figure 11. Stress change during optimization.

From the Ansys optimization results, we can see that all the optimization parameters and the optimization targets are convergent and meet the requirements. 


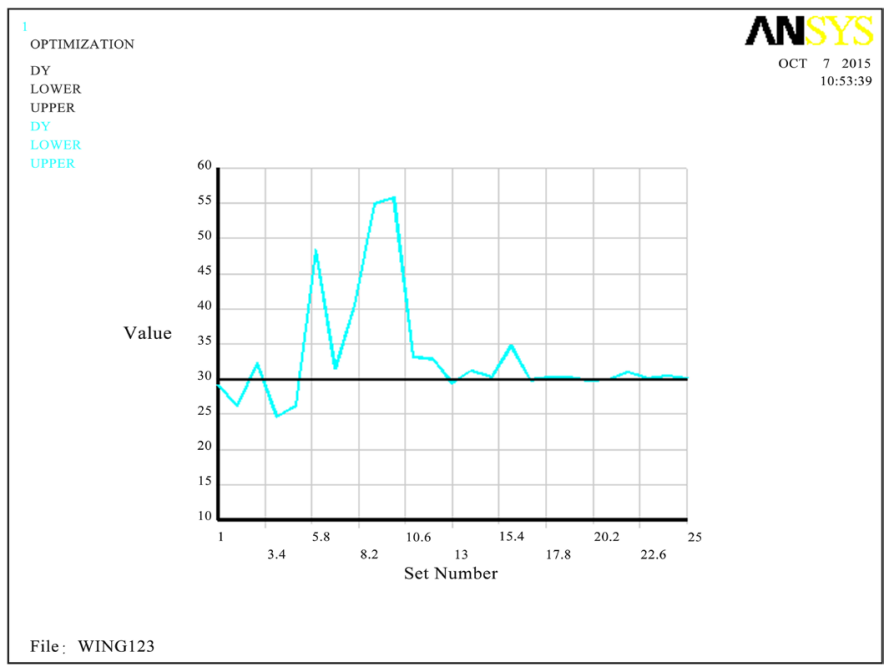

Figure 12. Deflection change during optimization.

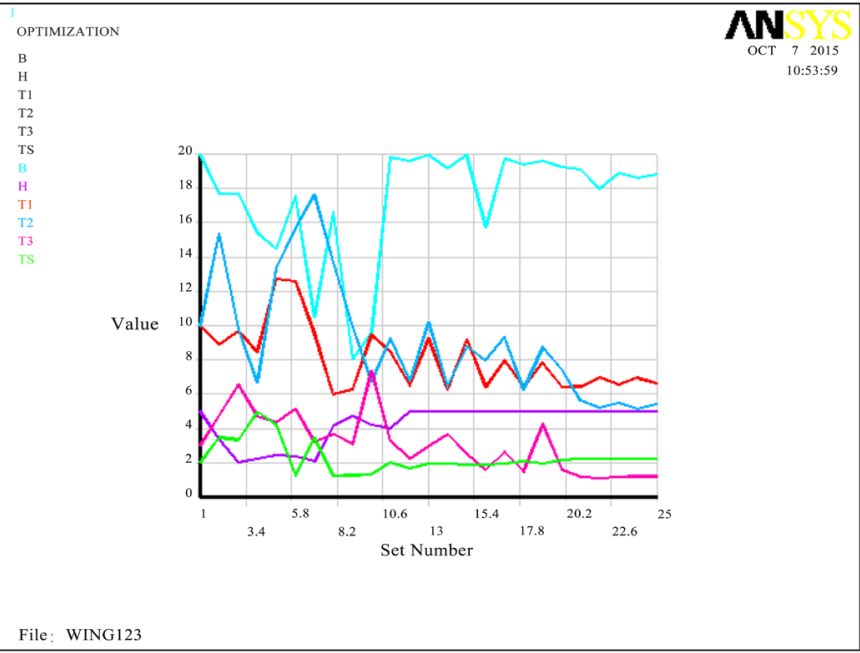

Figure 13. Geometric parameter change during optimization.

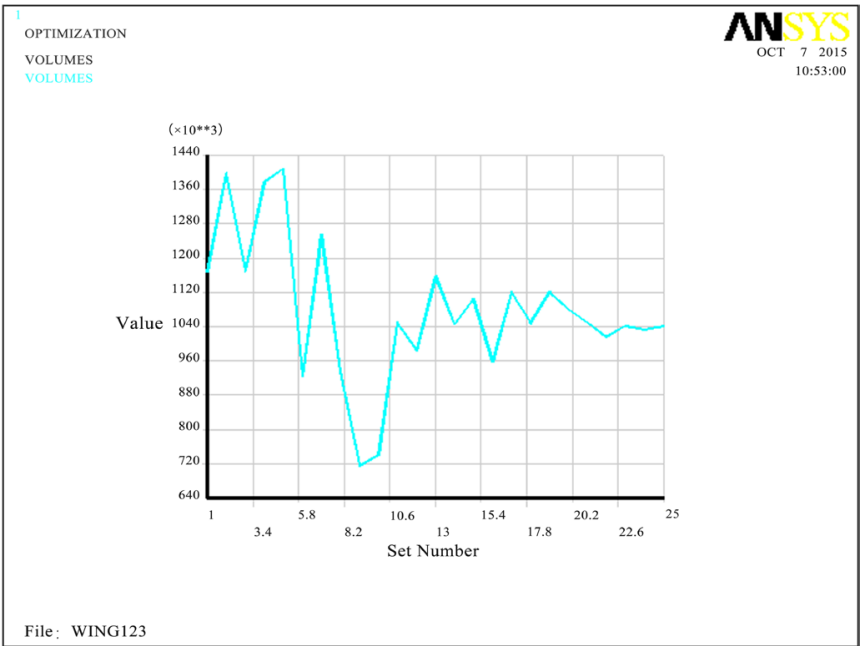

Figure 14. Volume change during optimization. 


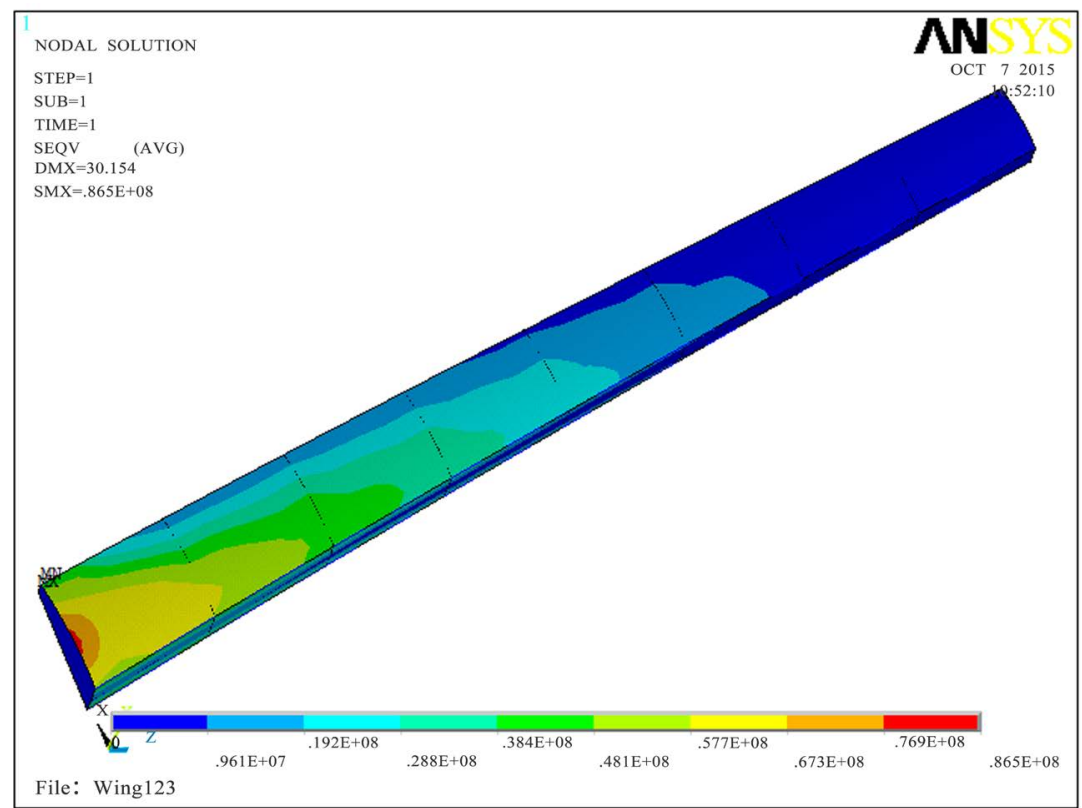

Figure 15. Stress cloud map.

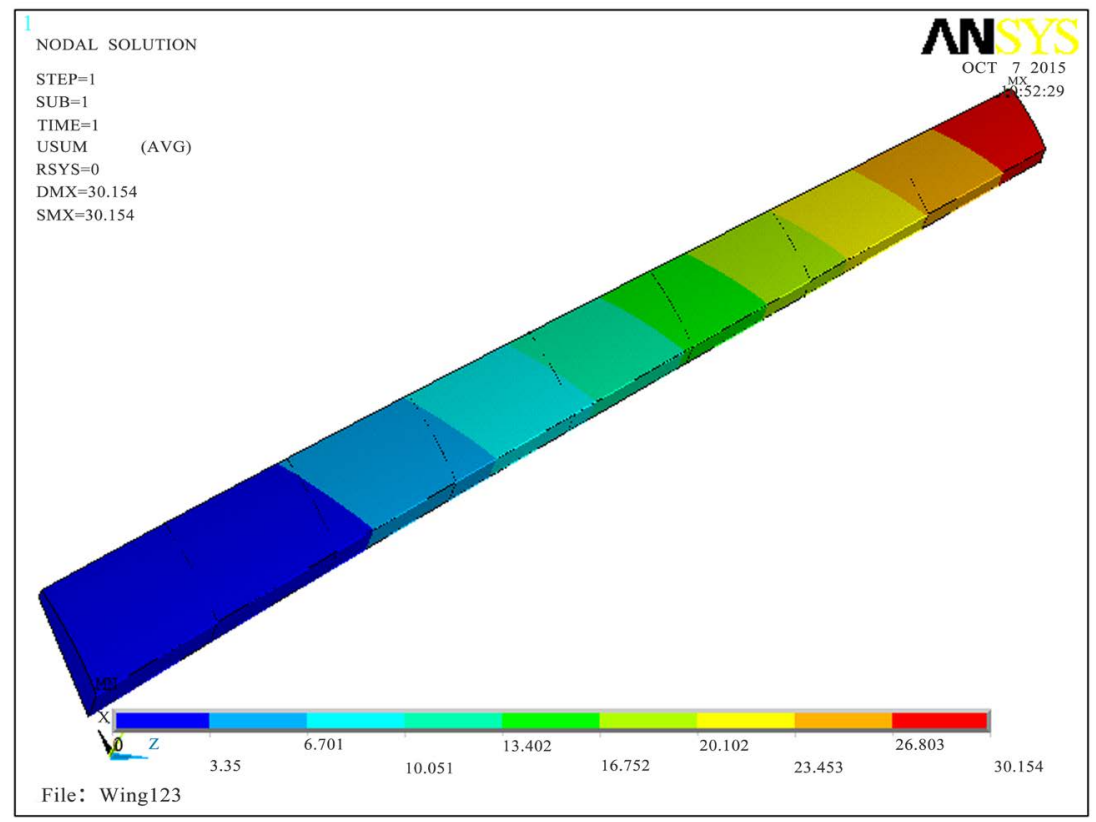

Figure 16. Strain cloud map.

The stress, the strain cloud graph is reasonable, the optimization results are effective for the volume reduction and optimization [10] [11] [12].

\subsection{CATIA Modeling}

Wing beams, wing ribs and web plates are used as skeleton support. Because the wings are smaller, the upper and lower edges of the wing and web are repaired according to the skin to ensure that the aerodynamic shape of the wing is smooth, and the wing can play its due role (Figures 17-19). 


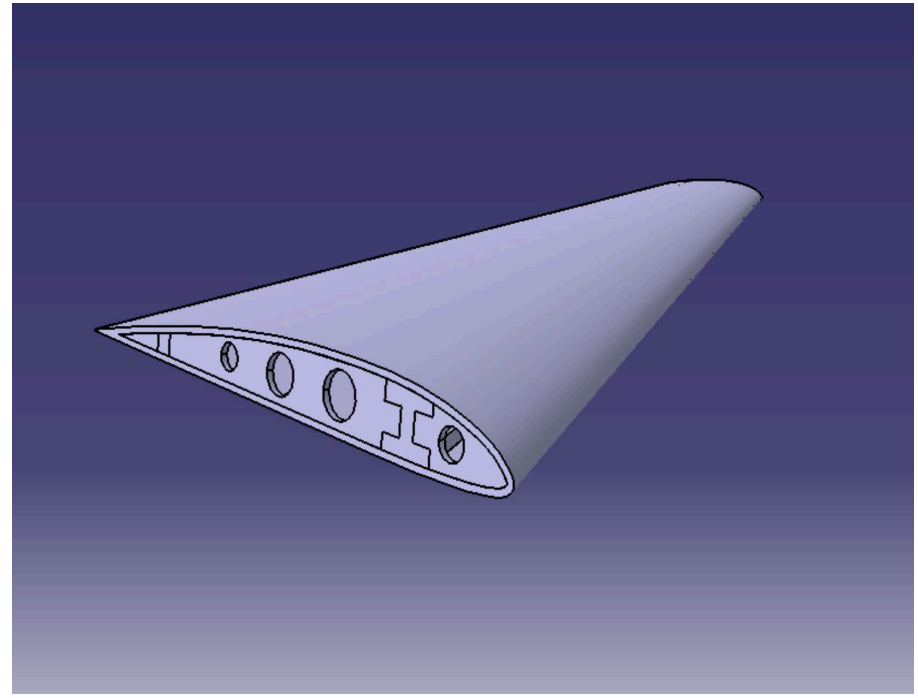

Figure 17. Overall wing structure form.

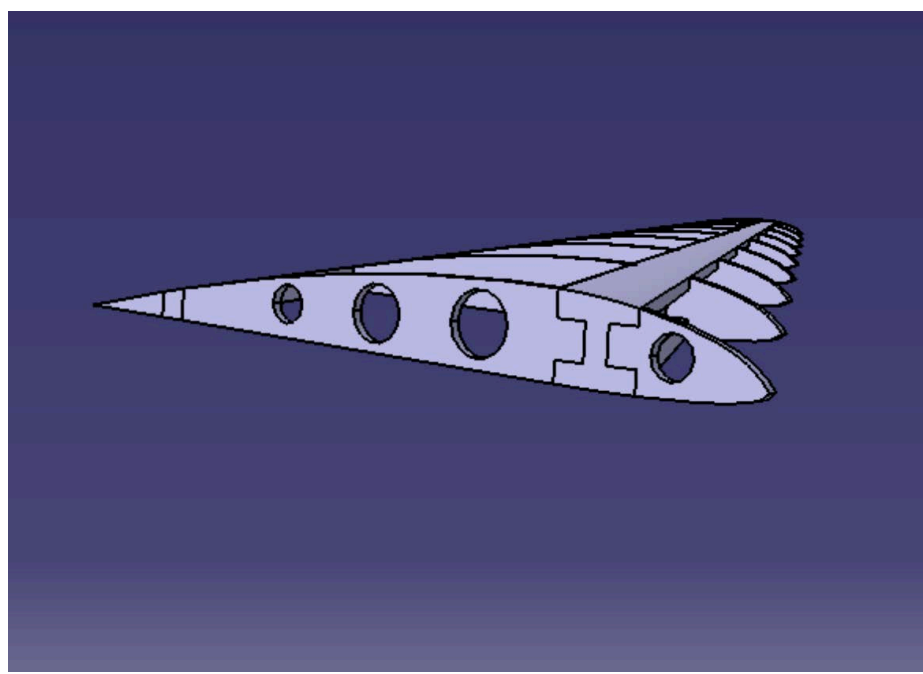

Figure 18. Wing skeleton.

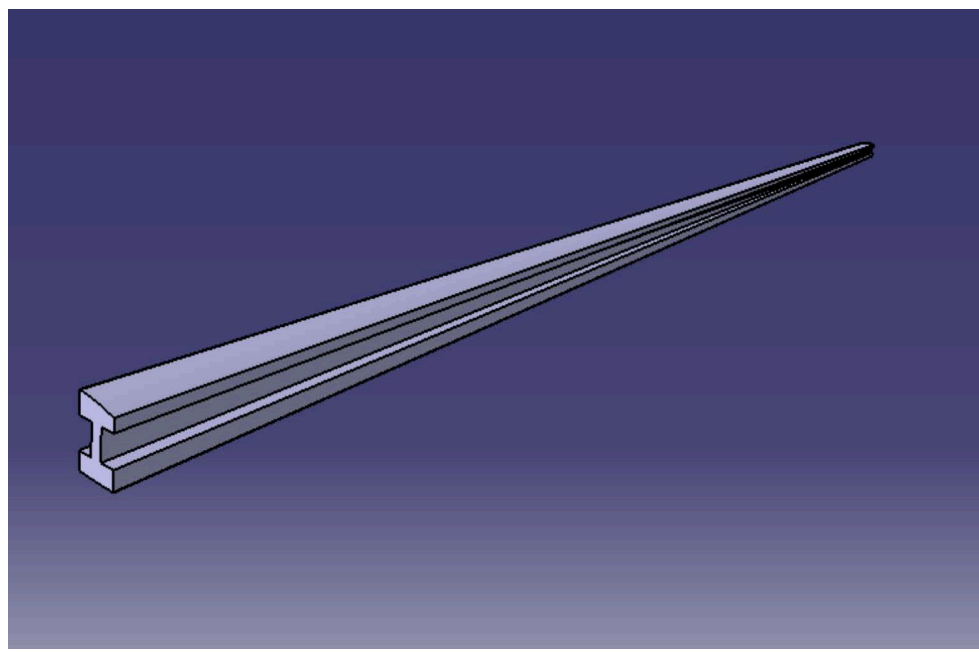

Figure 19. Wing beam. 


\section{Conclusion}

In this work, according to the work conditions, such as 100 Newton lift force and 50 Newton drag force, we compare several types of wings, such as beam-type, single-block-type and multi-ventral-plate-type. Finally, we chose beam-type wing. Then we made the detailed design on the beam, rib, skin and web. After structure design, we optimized the wing to reduce the weight of wing. At last, we use Catia to draw the 3D model of detailed parts for potential realistic production. The design and optimization for a fixed-wing UAV is finished.

\section{Conflicts of Interest}

The author declares no conflicts of interest regarding the publication of this paper.

\section{References}

[1] https://en.wikipedia.org/wiki/Wing

[2] Li, Z.N. (2010) Aircraft Structure Science. 2nd Edition, Beihang University Press.

[3] Raymer, D. (2012) Aircraft Design: A Conceptual Approach. 15th Edition. https://doi.org/10.2514/4.869112

[4] Hicks, R.M. and Henne, P.A. (1978) Wing Design by Numerical Optimization. Journal of Aircraft, 15, 407-412. https://doi.org/10.2514/3.58379

[5] Young, J., Walker, S.M., Bomphrey, R.J., Taylor, G.K. and Thomas, A.L. (2009) Details of Insect Wing Design and Deformation Enhance Aerodynamic Function and Flight Efficiency. Science, 325, 1549-1552. https://doi.org/10.1126/science.1175928

[6] Alexandrov, N., Lewis, R., Gumbert, C., Green, L. and Newman, P. (2000) Optimization with Variablefidelity Models Applied to Wing Design. 38th Aerospace Sciences Meeting and Exhibit, 841. https://doi.org/10.2514/6.2000-841

[7] Vicini, A. and Quagliarella, D. (1999) Airfoil and Wing Design through Hybrid Optimization Strategies. AIAA Journal, 37, 634-641. https://doi.org/10.2514/2.764

[8] NASA Wing Design Report, GRADES K-12.

[9] Fang, Z.P. (2005) Aeronautical Aircraft Flight Dynamics. Beihang University Press.

[10] Zhang, H.C. (2013) ANSYS 14.0 Theoretical Analysis and Engineering Application Examples. China Machine Press.

[11] Liu, X.T. (2015) ANSYS Workbench Structural Engineering Advanced Application. China Water \& Power Press.

[12] Wang, X.M. (2007) ANSYS Numerical Analysis of Engineering Structure. China Communications Press. 